\title{
Article \\ Propagation of International Supply-Chain Disruptions between Firms in a Country
}

\author{
Hiroyasu Inoue
}

Citation: Inoue, Hiroyasu. 2021.

Propagation of International Supply-Chain Disruptions between Firms in a Country. Journal of Risk and Financial Management 14: 461. https://doi.org/10.3390/jrfm14100461

Academic Editor: Pius Egbelu

Received: 17 July 2021

Accepted: 24 September 2021

Published: 1 October 2021

Publisher's Note: MDPI stays neutral with regard to jurisdictional claims in published maps and institutional affiliations.

Copyright: (C) 2021 by the author. Licensee MDPI, Basel, Switzerland. This article is an open access article distributed under the terms and conditions of the Creative Commons Attribution (CC BY) license (https:/ / creativecommons.org/licenses/by/ $4.0 /)$.
Graduate School of Information Science, University of Hyogo, Kobe 650-0047, Hyogo, Japan; inoue@gsis.u-hyogo.ac.jp

\begin{abstract}
This study shows how import and export shocks propagate through domestic supply chains using actual Japanese supply-chain data and a world input-output table (WIOT) based on firm-level agent-based simulations. We propose three different models with which to connect the domestic firms to a WIOT. Then, we estimate the value-added losses of Japanese firms caused by shocks of different magnitudes and durations originating in China, in the EU and the US, and globally. The volume and rates at which losses increase are very different across the connection models, which indicates that the assignment of international connections to firms matters greatly. The losses increase sublinearly as the duration expands, which indicates that the shock propagation ultimately saturates the economy. Rates of saturation differ substantially depending on the assignment of international connections. The losses increase superlinearly as the initial reduction rate increases. This occurs because there is a greater probability of one supplier being replaced by other suppliers if the reduction is smaller.
\end{abstract}

Keywords: supply chain; world input-output tables; simulation; propagation

\section{Introduction}

The structure of the global economy has changed over recent decades, particularly in the areas of international trade and industrial organization Gereffi et al. (2005). First, the volume of the international trade relative to GDP has grown rapidly since 1990 World Bank (2020). Not only the quantity but also the quality of international trade has changed in terms of hyperspecialized firm-to-firm relationships World Bank (2020). Concretely, corporations have vertically disintegrated, and each enterprising body has clarified its own competency Feenstra (1998). As a result, global supply chains are now the most complex they have been in history. One positive aspect of such advanced global supply chains is that a product or service can include a combination of high-quality products and services, and the entire economy is efficient because each enterprise can trade worldwide Christopher (2016). However, there are also downsides. One of the most critical downsides concerns supply-chain disruptions that arise from the complex nature of global supply chains.

A major cause of supply-chain disruptions are disasters. For example, the Great East Japanese Earthquake of 2011 reached a magnitude of 9.0 and is the fourth largest earthquake in the world occurring since 1900. The epicenter formed off the coast of northeastern Japan, a relatively underdeveloped region where many small and mediumsized suppliers in the automobile and electric machinery industries are located Ministry of Economy, Trade and Industry (2011). Since Japanese products and services are integrated into the world economy, global supply chains were affected. Rather, Thai, Filipino and Indonesian automobile and electrical component production was greatly reduced Ye and Abe (2012). Another example are the 2011 floods occurring in Thailand. These floods inflicted considerable damage to several Southeast Asian countries and the Sindh region of Pakistan. In particular, Thailand experienced severe flooding in its central region, including in Bangkok and parts of neighboring areas where many factories and businesses were 
located. The Thai economy is also integrated into global supply chains, and so these negative shocks transmitted into other countries. In particular, Japanese automotive and electrical component production declined greatly due to the disaster Chongvilaivan (2012).

Another nonnegligible cause of supply-chain disruptions are pandemics Chowdhury et al. (2021); Paul and Chowdhury (2020). COVID-19, a novel coronavirus disease, has been spreading worldwide since 2020, and by 9 June 2021, the total number of confirmed cases of COVID-19 reached 173,887,864, while the total number of deaths reached 3,744,378 Coronavirus Resource Center (2020). To prevent the spread of COVID-19, most countries have implemented unprecedentedly stringent restrictions. For example, Wuhan, the epicenter of the COVID-19 pandemic, was locked down from 23 January to 27 March 2020 with all public transportation and companies not essential to citizens' survival shut down (Reuters, 11 March 2020). Apparently, the lockdown greatly affected Wuhan's economy. Moreover, because Wuhan, known as the "Chinese Detroit", is an automotive industrial center and supplies automotive parts and components to domestic and foreign manufacturers, the effects of the lockdown propagated to other countries through supply chains. For example, Honda, a Japanese automobile manufacturer that operates plants in Wuhan, reduced its production of automobiles in Japan due to a lack of parts supplies from China in early March 2020 (Nikkei Newspaper, 2 March 2020).

The disruptions described above represent a systemic risk that is difficult to control, especially at the firm level. This is the case because even if a firm identifies disaster-prone trade partners, indirect suppliers or clients are spread across widely interconnected supply chains. Thus, it is beyond the capacity of firms to control and monitor supply chains Kimura and Ando (2005).

As a tool for studying global supply chains, world input-output tables (WIOTs) have been widely used Ayadi et al. (2021); Baldwin and Lopez-Gonzalez (2015); Dietzenbacher et al. (2013); Timmer et al. (2015). A major limitation of input-output tables is that they can be used to calculate the upstream impacts but not downstream impacts Thomas and Helgeson (2021). To mitigate this limitation, i.e., to incorporate downstream impacts, the adaptive regional input-output (ARIO) inventory model is proposed Hallegatte (2014) and applied to WIOTs Guan et al. (2020) to discuss the impact of COVID-19. In addition, in reality, supply chains are sparse and complex networks of firms engaged in trade, and input-output tables are aggregates of these firm-level trade relationships by sector or country-sector and a densely connected network of sectors. Therefore, firm-level networks allow us to see not only the attributes of each firm but also the complex nature of supply chains. This limitation of studying the global supply chains through sector-level data is also indicated in the World Bank's report World Bank (2020). In addition, the number of links that each firm has, also known as a firm's degree, follows a power-law distribution Inoue and Todo (2019a), as is commonly observed in many natural and societal networks Barabási (2016). This means that if a hub (a firm with many trade relationships) is affected, many other firms will be affected and vice versa. Such relationships and outcomes cannot be observed in an input-output table. This is simply the case because input-output tables do not capture such skewed distributions of the number of links.

Currently, there are no complete global supply-chain data for the firm level. On the other hand, Japanese country-wide supply-chain data that cover approximately $1.6 \mathrm{M}$ firms and $6 \mathrm{M}$ trade relationships exist Fujiwara and Aoyama (2010). In addition, based on these domestic supply-chain data, simulations have been conducted to determine how negative shocks, i.e., the Great East Japanese Earthquake Inoue and Todo (2019a) and the COVID-19 pandemic Inoue and Todo (2020), have propagated through the Japanese economy. However, the propagation of negative shocks to imports and exports through global supply chains into domestic firm-level supply chains has not been studied.

To fill the above research gap, the present study shows how import and export shocks are propagated into domestic supply chains. In particular, we use actual Japanese supplychain data and connect them to a WIOT. Since the former are of the firm level and the latter is of the sector level, we propose three different models for estimating the imports and 
exports of each firm. Then, we separate China, the EU, and the US, i.e., China and Western countries, from the rest of the world because China, the EU and the US are geopolitically and economically important to Japan.

The paper proceeds as follows. In the next section, we describe the material and method we use. Then, we present the results in Section 3, and we discuss them and conclude the paper in Section 4.

\section{Material and Method}

\subsection{Supply-Chain Data}

The firm-level supply-chain data used in this study are taken from the Company Information Database and Company Linkage Database compiled by Tokyo Shoko Research (TSR), one of the largest credit research companies in Japan. The former database includes information on the attributes of firms, including their locations, industries, sales, and numbers of employees, and the latter database includes the major customers and suppliers of each firm. In particular, industrial sectors are classified according to the Japan Standard Industrial Classification (JSIC) MIC (2013). Due to issues of data availability, we use data on firm attributes and supply chains for 2016. These data serve as our domestic supply-chain data, and we relate these data to import and export data, i.e., the World Input-Output Database (WIOD). Further details are provided in Section 2.4.

The TSR data include information on Japanese firms and their relationships. Regarding relationships, the maximum number of suppliers and clients each firm can report is 24 . However, when we consider supplier-client relations running in the opposite direction, more than 24 suppliers or 24 clients can be found for each firm. The TSR data include the headquarter addresses of the firms.

The data cover 1,668,567 firms and 5,943,073 supply-chain links. Hence, our data identify the major supply chains of most firms in Japan. Because the transaction value of each supply-chain link is not available from the data, we estimate sales from a supplier to each of its customers and to consumers using the total sales of the supplier and the 2015 inputoutput tables for Japan Ministry of Internal Affairs and Communications et al. (2015). For this estimation process, we remove firms without sales information. Accordingly, 966,627 firms and 3,544,343 links are included in our final analysis. Although the firms included in the TSR data are classified into 1460 industries according to the JSIC MIC (2013), we simplify the industries into the 187 industries identified in the IO tables. To estimate transaction volumes, first, we divide each supplier's sales to its clients proportionate to the clients' sales to create a tentative sales value. Second, we refer to the 2015 Japanese IO table Ministry of Internal Affairs and Communications et al. (2015) to transform these tentative values such that the total volume corresponds to GDP. Specifically, we aggregate the tentative values at the firm-pair level to calculate total sales for each pair of industrial sectors. We then divide total sales for each industrial sector pair by the transaction values for the corresponding pair included in the IO tables. The ratio is then used to adjust the transaction values between firms. The final consumption of each industrial sector is assigned to all firms in the sector using their sales volumes as weights.

In the supply-chain data described above, the degree of each firm, or its number of links, follows a power-law distribution Inoue and Todo (2019a) as often found in the literature Barabási (2016). The average path length between firms, or the number of steps in the supply chain between them, is 4.8 , indicating a small-world network. Using the same dataset, previous studies Fujiwara and Aoyama (2010); Inoue and Todo (2019a) have found that $46-48 \%$ of firms are included in the giant strongly connected component (GSCC), all firms that are indirectly connected to each other through supply chains. The large size of the GSCC clearly shows that the network has a significant number of cycles, diverging from the common image of a layered or tree-like supply-chain structure. 


\subsection{World Input-Output Table}

Since the present study examines the effect of import and export shocks on domestic firms, it is necessary to identify the international connections of domestic firms. To do so, we use the WIOD, which contains an annual time-series of WIOTs Timmer et al. (2015). In particular, we use the WIOT for 2014. This table indicates the trade volume between sectors across countries. There are 43 partner countries and 56 sectors for each country. Moreover, the table includes 28 EU countries, the US, China, and Japan. The sectors are classified according to the International Standard Industrial Classification (ISIC) Statistics Division, Department of Economic and Social Affairs, United Nations (n.d.). In particular, we use import and export connections to Japan and the volume of connections taken from this table.

In the present study, import and export shocks are given at the sectoral level based on the WIOT. Since the WIOT uses the ISIC and the domestic supply-chain data use the JSIC, we use a correspondence table Statistics Division, Department of Economic and Social Affairs, United Nations (n.d.) to match codes between them.

\subsection{Model}

We employ the dynamic agent-based model of Inoue and Todo (2019a, 2019b), an extension of Hallegatte and Henriet (2008)'s model, which assumes that supply chains exist at the firm level. In the model, firms use various intermediate goods as inputs and provide a sector-specific product to client firms and final consumers. Firms have an inventory of intermediate inputs from suppliers. However, they have no inventory of completed products, and the completed product is immediately delivered to clients. In addition, there are no prices and no market mechanisms. Supply chains are predetermined and do not change over time. Therefore, each firm uses a firm-specific set of inputs and does not change the input set. In addition, each firm is linked to fixed suppliers and customers and does not add any new links, even after a supply-chain disruption. Accordingly, the model and our analysis focus on short-term changes in production.

As mentioned in the last paragraph, the model has been revised along with the literature. Representations of firms, such as sectors, is insufficient to model the propagation of shocks, since supply-chain disruptions are due to bottlenecks that mainly come from supplier failures. Therefore, a disaggregated input-output model was first proposed Hallegatte and Henriet (2008) in this strand of the literature Battiston et al. (2007); Gatti et al. (2005); Weisbuch and Battiston (2007). The inventory mechanism was incorporated later Hallegatte (2012). Then, the model was comprehensively discussed in terms of the networks structure Henriet et al. (2012). Although the purpose of the models is to study macroeconomic behavior of the firm-level network, past studies lack an actual macro firm-level network. Instead, they have used artificial networks created from the input-output table. The model was first applied to nationwide firm-level networks Inoue and Todo (2019b) in this context. Then, the probabilistic distribution of inventory and a rationing mechanism considering relative demand were introduced instead of the constant distribution and applied to natural disasters Inoue and Todo (2019a) and COVID-19 shocks Inoue and Todo (2020); Inoue et al. (2021a, 2021b).

In the initial state before an economic shock, the daily trade volume from supplier $j$ to client $i$ is denoted by $A_{i, j}$, and the daily trade volume from firm $i$ to final consumers is denoted by $C_{i}$. Then, the initial daily production of firm $i$ is given by the following:

$$
P_{\text {ini } i}=\Sigma_{j} A_{j, i}+C_{i} .
$$

On the $t$-th day after the initial state, the demand from the previous day for firm $i$ 's product is $D_{i}^{*}(t-1)$. The firm thus places orders with each supplier $j$ such that its stock of product from supplier $j$ can be used to meet this demand; therefore, $A_{i, j} D_{i}^{*}(t-1) / P_{\text {ini } i}$. We assume that firm $i$ maintains an inventory of the intermediate goods produced by firm $j$ on day $t, S_{i, j}(t)$ and aims to restore this inventory to a level equal to a given number of days $n_{i}$ corresponding to the use of supplier $j$ 's product. Constant $n_{i}$ is assumed to be Poisson 
distributed with mean $n$, which is a parameter. In addition, $n_{i}$ does not take a value of less than 4 . The value is found through experiments to find the minimum inventory size that does not cause a bullwhip effect (a fluctuation of production levels). Furthermore, following Inoue and Todo (2019a), in which parameter values are calibrated using the Great East Japanese Earthquake, we assume that the average of the Poisson distribution is 10 . When the actual inventory is smaller than its target, firm $i$ gradually increases its inventory by $1 / \tau$ of the gap so that it reaches the target in $\tau$ days, where $\tau$ is assumed to be 6 to follow the original model Hallegatte (2008). Therefore, firm $i$ 's order to its supplier $j$ on day $t$, denoted by $O_{i, j}(t)$, is given by the following:

$$
O_{i, j}(t)=A_{i, j} \frac{D_{i}^{*}(t-1)}{P_{\text {ini } i}}+\frac{1}{\tau}\left[n_{i} A_{i, j}-S_{i, j}(t)\right],
$$

where the inventory gap is shown in brackets. Accordingly, the total demand for the product of supplier $i$ on day $t, D_{i}(t)$, is given by the sum of the final demand from final consumers and total orders from customers as follows:

$$
D_{i}(t)=\Sigma_{j} O_{j, i}(t)+C_{i}
$$

Suppose that an economic shock affects the economy on day 0 and that firm $i$ is directly affected. Subsequently, a proportion $\delta_{i}(t)$ of the production capital of firm $i$ malfunctions. In this study, $\delta_{i}$ is determined by the country and sector to which firm $i$ belongs and the duration of the imposed negative shock. Hence, the production capacity of firm $i$, defined as its maximum production, $P_{\mathrm{Cap} i}(t)$, is given by the following:

$$
P_{\operatorname{cap}_{i}}(t)=P_{\operatorname{ini} i}\left(1-\delta_{i}(t)\right) .
$$

The production of firm $i$ might also be limited by a shortage of supplies. Because we assume that firms in the same sector produce the same product, the supply shortage experienced by firm $j$ in sector $s$ can be compensated for by ordering supplies from firm $k$ in sector $s$. Firms cannot find new suppliers for affected suppliers after the shock to the model, as we assume fixed supply chains. Thus, the total inventory of the products delivered by firms in sector $s$ to firm $i$ on day $t$ is as follows:

$$
S_{\text {tot } i, s}(t)=\Sigma_{j \in s} S_{i, j}(t)
$$

The initial consumption of products from sector $s$ by firm $i$ before the shock is also defined for convenience as follows:

$$
A_{\text {tot } i, s}=\Sigma_{j \in s} A_{i, j}
$$

The maximum possible production of firm $i$, limited by the inventory of product from sector $s$ on day $t, P_{\text {proi,s }}(t)$, is given by the following:

$$
P_{\text {pro } i, s}(t)=\frac{S_{\text {tot } i, s}(t)}{A_{\text {tot } i, s}} P_{\text {ini } i} .
$$

Then, we can determine the maximum production of firm $i$ on day $t$ given its production capacity, $P_{\text {Cap } i}(t)$, and its production constraints due to the supply shortage, $P_{\text {pro } i, s}(t)$ as follows:

$$
P_{\max i}(t)=\operatorname{Min}\left(P_{\operatorname{cap} i}(t), \operatorname{Min}_{\mathcal{S}}\left(P_{\text {pro } i, s}(t)\right)\right) .
$$

Therefore, the actual production of firm $i$ on day $t$ is given by the following:

$$
P_{\text {act } i}(t)=\operatorname{Min}\left(P_{\max i}(t), D_{i}(t)\right) .
$$


When demand for a firm's product is greater than its production capacity, the firm cannot completely satisfy this demand, as denoted by Equation (9). In this case, firms must ration their sales to their customers. Following previous work Hallegatte and Henriet (2008), the rationing policy prioritizes clients and final consumers making small orders relative to their initial (preshock) orders instead of treating all clients and consumers equally in the sense of absolute volume.

Suppose that firm $i$ has client $j$ and a final consumer. Then, the order ratios, i.e., the order sizes relative to the initial state, from client $j$ and the final consumer are denoted by $O_{j, i}^{r e l}$ and $O_{c}^{r e l}$, respectively. $O_{\min }^{r e l}=\operatorname{Min}\left(O_{j, i}^{r e l}, O_{c}^{r e l}\right)$ is calculated. If $r \leq\left(\sum_{j} O_{\min }^{r e l} O_{j, i}+\right.$ $O_{\min }^{r e l} C_{i}$ ), where $r$ is the remaining production of firm $i, O^{r e a}$ is calculated such that it satisfies $r=\left(\sum_{j} O^{r e a} O_{j, i}+O^{r e a} C_{i}\right)$. Then, we have $O_{j, i}^{*}=O^{r e a} O_{j, i}+O_{j, i}^{s u b} O_{j, i}$ and $C_{i}^{*}=$ $\mathrm{O}^{\text {rea }} C_{i}+\mathrm{O}_{c}^{s u b} C_{i}$, where the realized order from firm $j$ placed with supplier $i$ is denoted by $O_{j, i}^{*}(t)$, and the realized order from the final consumer is $C_{i}^{*}$. If $r>\left(\sum_{j} O_{\min }^{r e l} O_{j, i}+\right.$ $O_{\min }^{r e l} C_{i}$, we add $O_{\min }^{r e l}$ to $O_{j, i}^{s u b}$ and $O_{c}^{s u b}$, where $O_{j, i}^{s u b}$ and $O_{c}^{s u b}$ are temporal variables used to calculate the realized orders and are initially set to zero. Then, we subtract $\left(\sum_{j} O_{\min }^{r e l} O_{j, i}+O_{\min }^{r e l} C_{i}\right)$ from $r$ and remove the client or final consumer denoted by $O_{\min }^{r e l}$ from the calculation. We repeat this process until $r$ is equal to zero. Algorithmic and detailed explanations are found in Inoue and Todo (2020).

Under this rationing policy, the total realized demand faced by firm $i, D_{i}^{*}(t)$, is given by the following:

$$
D_{i}^{*}(t)=\Sigma_{j} O_{i, j}^{*}(t)+C_{i}^{*},
$$

where the realized order from firm $i$ placed with supplier $j$ is denoted by $O_{i, j}^{*}(t)$ and that from the final consumers is denoted by $C_{i}^{*}$. Based on the firms' production and procurement activities on day $t$, the inventory of firm $j^{\prime}$ s product held by firm $i$ on day $t+1$ is updated to the following:

$$
S_{i, j}(t+1)=S_{i, j}(t)+O_{i, j}^{*}(t)-A_{i, j} \frac{P_{\text {act } i}(t-1)}{P_{\text {ini } i}} .
$$

In the present study, we investigate how international shocks propagate through domestic supply chains. Therefore, we must consider not only the domestic relationships among firms but also their international relationships. As mentioned in Section 2.2, we do not use firm-level data to identify international relationships. Instead, we use data from the 2014 WIOT to infer the import and export relationships. If there are imports from a given sector in a country to Japan, a firm is allocated to that country's sector to allow the above model to be applied since there is no sector-level agent in the model. Simply put, each sector is modeled as a firm. This approach has been used in the literature Hallegatte (2008). There is no supplier for the international sector. On the other hand, for exports from Japan, firms are not allocated to foreign sectors. Instead, exports from Japan to a sector in another country are treated as the demand from final consumers for the firm.

Although we describe how we treat imports and exports in the model, it is not yet clear which domestic firms are connected to the international sectors and what the magnitude of the connection is in terms of both imports and exports. These points are clarified in Section 2.4.

Regarding negative import shocks, the international sector (modeled as a firm) reduces its supply. The supply of products from the directly affected sector to its domestic customer firms then declines. Therefore, one way for domestic customer firms to maintain their current level of production is to use their inventory of inputs. Alternatively, domestic customers can procure inputs from other suppliers in the same industry to which they were already connected before the shock, provided these suppliers have additional production capacity. If firm inventory and inputs from substitute suppliers are insufficient, the domestic customer firms must reduce their production because of the shortage of inputs. On the other hand, since supply from the import sector to the domestic customer firm is reduced and the customers reduce their production, customers' demand for parts and components 
to their other suppliers immediately declines, and thus these suppliers must decrease their production. Because demand for products from the suppliers' suppliers also declines, the negative effect of the shock propagates to upstream firms. Such upstream propagation is likely to be faster than downstream propagation because of inventory buffers and input substitution, which hinder downstream propagation. In summary, when the import shock affects domestic firms, both upstream and downstream domestic firms are also affected. The negative export shock is modeled as a reduction in the demand of final consumers for the goods of each domestic firm. After this shock, the demand of the affected firms for their suppliers' goods also declines. In this case, the effects of the shock are not propagated to downstream firms because there is no reduction in production capability.

Since the model does not include connections between international sectors, the propagation discussed above is limited to domestic supply chains and their relationships to imports and exports. In the long run, the lack of international connections outside of Japan may cause inaccuracies, but the estimation period used in the present study is less than a year. Therefore, the negative impact of this limitation of the model should be minor.

\subsection{Simulation Procedures}

\subsubsection{Complete Connection Model}

Section 2 has thus far described the domestic supply-chain data, WIOT, and simulations. However, one more step is needed to run the model. Since import and export shocks are given at the sectoral level and the domestic supply chains are defined at the firm level and not at the sectoral level, there is a difference in granularity between the datasets. Therefore, the way in which domestic firms are connected to international sectors should be defined. In the present study, we examine three ways to account for the correspondence between them. Please note that if there are data that describe the import and export partners that a domestic firm has, we do not need to consider this issue.

The first way to connect a domestic firm to the import and export sectors is to assume that all domestic firms in a sector have export and import connections. This is the most extreme case for three reasons. First, in reality, not all firms purchase imports and sell exports. Second, similar to the first reason, even if a firm has international relationships, this does not necessarily mean that the firm has both import and export relationships. Third, even if a firm has import or export relationships, the firm normally does not have trade relationships with firms from all countries in the WIOT. Therefore, the estimation of this model requires many connections between domestic firms and international sectors, and this model estimates the maximum number of firms that could be affected by the shock.

Since the trade volume related to each connection between a domestic firm and an international sector is not known, it should be estimated. Each connection, i.e., each domestic sector import relationship with a foreign sector, can be obtained from the WIOT. The volume of imports is also obtained from the WIOT and divided among the domestic firms (importers) in proportion to the importers' sales. Export volumes are estimated in the same way. Hereafter, this model is called the "complete connection model".

As mentioned in Section 2.3, an agent that is no different from a firm-level agent in the model acts as a foreign sector for imports. Therefore, the trade volume calculated as described above is the supply volume from a foreign sector to a domestic firm in the model. On the other hand, exports are purchased by final consumers in the model, so there is no agent for exports. Instead, the export volume is added to the final consumption of the domestic firms' goods. This setup is applied to the other models as well.

\subsubsection{Actual Number Model}

Since the complete connection model includes the largest possible number of importers and exporters, we limit this number to be more realistic by using statistics on the actual number of importers and exporters in each industry Ministry of Trade, Enterprise and Industry (2019). Since it is not clear which firms are actually importers or exporters, we 
choose the same number of firms from the statistics in descending order of sales. This choice reflects the assumption that large firms tend to engage in international trade since international trade incurs costs. The volume of each connection is estimated using the same method as that used in the "complete connection model", i.e., the import (export) volume is divided among the chosen domestic firms in proportion to the importers' (exporters') sales. Hereafter, we call this the "actual number model".

Although the actual number model reflects the actual numbers of importers and exporters, it is still flawed. First, the choice of which firms are likely to be importers and exporters is made on an ad hoc basis, although relatively large firms are involved in importing and exporting. Second, the firms with the largest sales volumes are connected to all foreign countries in the WIOT in the model. This is also unlikely to be true. However, compared to the complete connection model, the exogenous shock propagation to domestic firms is expected to be milder and more realistic.

\subsubsection{Single-Connection Model}

Since the actual number model is unrealistic because it fixes which firms are involved in all the import and export relationships, we propose another model in which only one firm is chosen to act as an importer (exporter) from each foreign sector. The firm is chosen by a probability proportional to its sales. The volume of each connection is the whole volume found between sectors shown in the WIOT. Although this probabilistic model is not very realistic, it is important because it provides a lower bound in terms of the number of connections.

\subsubsection{Scenarios}

We consider the following three major scenarios: (1) a shock starting in China, (2) a shock starting in the EU and the US, and (3) a shock starting in all countries outside of Japan. As discussed in Section 1, considering the spread of COVID-19 and the antipandemic measures taken Guan et al. (2020), it is important to examine China by itself because of its importance as a major trade partner for Japan and given the geopolitical situation in Japan. In addition, since Western countries are strongly connected not only politically but also economically, it is also important to examine them separately. Moreover, considering the recent decoupling of China and the Western countries, a comparison of their effects on Japan is also important.

For each major scenario, we consider four different reductions: $20 \%, 40 \%, 60 \%$, and $80 \%$ reduction rates. For each rate, the industries in the focal country reduce their imports and exports with Japan by that rate. For example, a 20\% reduction in the Chinese shock scenario means that all industries in China reduce their transactions with Japan by $20 \%$.

Furthermore, we consider four different short durations and three different long durations: 1, 2, 3, and 4 weeks for the short durations and 2, 4, and 6 months for the long durations. Therefore, there are $84(=3 \times 4 \times 7)$ scenarios to examine. For each scenario, we run 10 Monte Carlo simulations. Although the model is deterministic, there is randomness in the initial inventory sizes. See Section 2.3 for further details regarding the model.

\section{Results}

Figure 1 presents the results of the simulations. Each bar shows a total loss percentage. The total loss indicates the lost value added that would have been produced if there had been no shock of the indicated duration. Please note that the colored parts of the bar plots indicate the "difference" relative to a smaller reduction rate. For example, the loss rate corresponding to the $40 \%$ reduction rate is a sum of the loss rate corresponding to the $20 \%$ and $40 \%$ reduction rates in this plot.

The first point to note from the results, is that there are differences between country scenarios. For each connection model, the value-added loss rate is the largest for the global shocks, followed by shocks from the EU and the US, with Chinese shocks generating the smallest value-added loss rate. This order is plausible when we consider the number of 
countries involved. However, the magnitudes of the loss caused by the Chinese shock in the complete connection and actual number models are very large in the sense that the loss is due to only one country and is roughly half of that caused by EU and US shocks or more depending on the connection models. This result indicates the importance of China to Japanese supply chains. Additionally, the results indicate the importance of the EU and the US because the losses from shocks originating in these regions are comparable to the losses estimated for the global scenarios. Although in 2015, the value of Japanese trade with China reached 326 trillion yen (21.2\% of Japan's total trade value), that value of Japanese trade with the EU and the US reached 393 trillion yen (25.9\% of Japan's total trade value), and that for all countries reached 1540 trillion yen Ministry of Finance (2021), China, the EU and the US show large loss estimations. The single-connection model shows extremely small loss rates for China compared with other countries, which will be explained later in terms of differences in the model.

The second point to note, is that the results depicted in Figure 1 also indicate that the value-added losses are the greatest in the complete connection model, followed by those in the actual number model, with the single-connection model generating the smallest losses. Importantly, since the import and export volumes are taken from the WIOT, the trade volumes used in each connection model are identical. Therefore, the differences in value-added losses are due to the number of firms with international connections. Since the number of connected domestic firms is the lowest in terms of the possible numbers of connections in the single-connection model, the estimated losses are extremely small. If a domestic firm reduces its imports by a given rate, that importing firm's production is also reduced by (up to) the same rate (after its input inventory is depleted). The import reduction shock affects all importing firms. Therefore, if there are more importing firms, there are more reductions in production. This mechanism drives the differences between the connection models.

The above explanations refer to import shocks. Regarding exports, however, there is no mechanism that amplifies the shock. This is the case because exports are not used as inputs to other firms in the simulation model.

In addition, the differences in the value-added loss rates between the models are very large. These results indicate that the assignment of imports to firms matters a great deal. Therefore, it may not be appropriate to make naive assumptions, such as the assumption that a sectoral-level supply-chain model is equivalent to a firm-level supply-chain model.

Figure 2 shows the results for the scenarios with longer-lasting shocks. In contrast to Figures 1 and 2 clearly shows that the losses increase sublinearly as the duration extends, which is likely because shock propagation has saturated the economy. It should be noted again that each bar shows a total loss percentage and not total loss volume itself. From the $80 \%$ reduction scenarios, we can clearly see the effects of saturation. In all models, the gap between 4 and 6 months is smaller than that between 2 and 4 months. Shock propagation becomes saturated simply because the shock ultimately propagates through the supply chains, but the propagation process takes time. If a connection model includes many import and export connections, it is more quickly saturated. Again, sectoral-level supplychain models cannot account for this issue and are therefore unlikely to be equivalent to firm-level supply-chain models.

Another notable finding shown by Figure 1 is that although the reduction rates change linearly, the loss rates increase superlinearly in all scenarios. As one of the most visible examples, the results for the complete connection model of a global shock lasting 2 weeks clearly show different loss rates for uniformly different reduction rates. We might imagine that if imports and exports are reduced by $20 \%$ and then by $40 \%$, the loss rate for the $40 \%$ reduction would simply be double that for a $20 \%$ reduction, but the loss rate for a $40 \%$ reduction is more than double. Therefore, the losses increase superlinearly relative to the reduction rates. These results can be explained by substitution. If a supplier delivers a smaller supply than its preshock level because of import reduction and if there is no substitution, the focal firm reduces its production. On the other hand, if the reduction in 
inputs is compensated for by other suppliers to the focal firm, the reduction in production at the focal firm is mitigated. In this case, it is easier to find a substitute for the input loss if the input loss is small. This is the case because substitution happens only when another supplier has surplus production capacity and such capacity is limited. As a result, a higher rate of reduction causes higher value-added loss rates.

\section{Complete connection model}

China

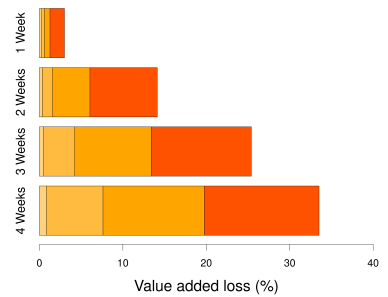

Actual number model

China

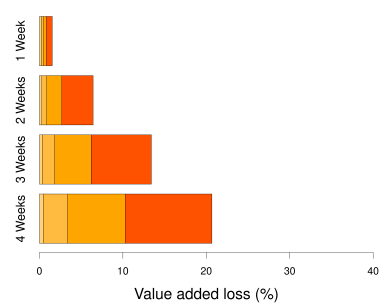

Single-connection model

China

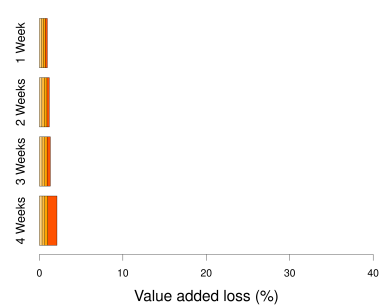

Europe and the United States

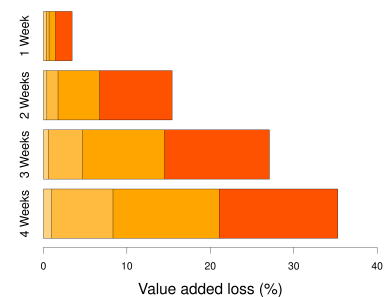

Europe and the United States

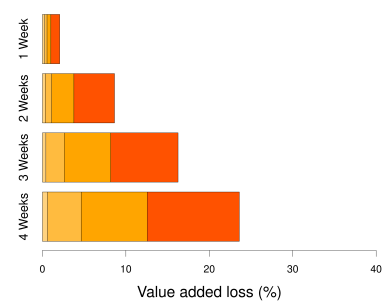

Europe and the United States

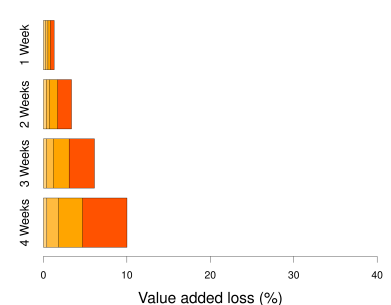

Global

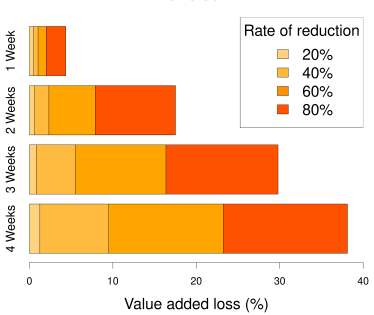

Global

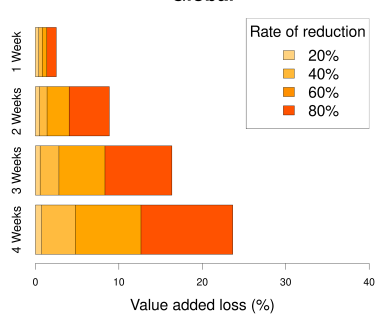

Global

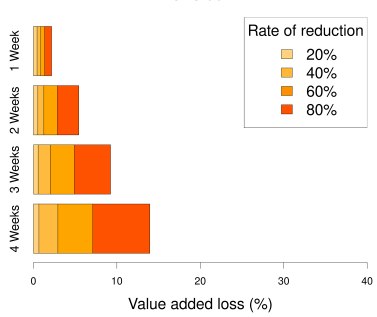

Figure 1. Simulation results (short term). These bar plots show the value-added loss percentages. The bar plots are not stacked but cumulative. For example, the darkest orange color for the $80 \%$ reduction rate shows the difference in value-added loss relative to that of a $60 \%$ reduction rate. The horizontal axis shows the value-added loss rate, which is the lost value added that would have been obtained if there had been no exogenous shocks divided by the value added without shocks. Each bar corresponds to a shock duration. The upper, middle, and lower panel rows correspond to the results for the complete connection, actual number, and single-connection models, respectively. 


\section{Complete connection model}

China

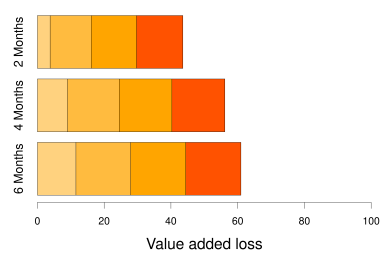

Actual number model

China

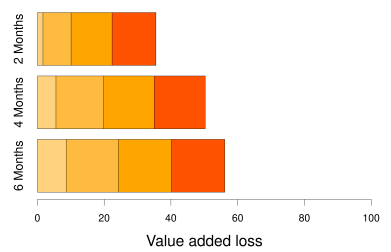

Single-connection model

China

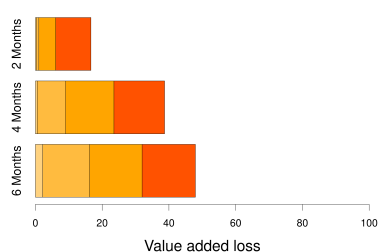

Europe and the United States

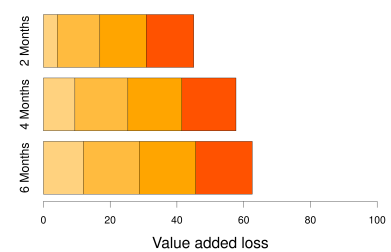

Europe and the United States

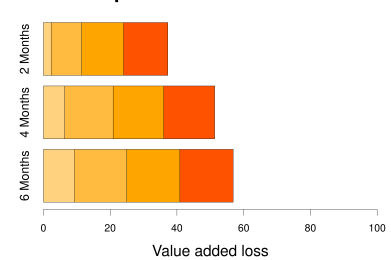

Europe and the United States

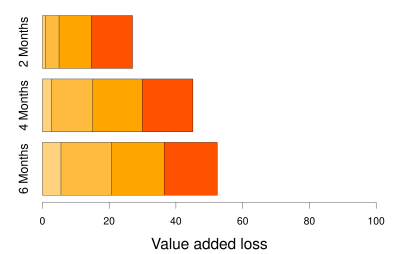

Global

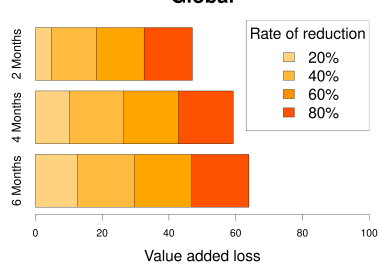

Global

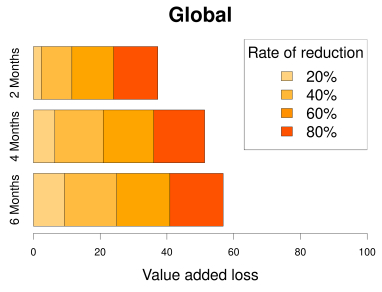

Global

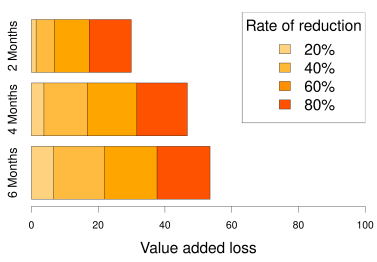

Figure 2. Simulation results (long term). The setup of the figure is the same as that for Figure 1. The horizontal axis shows the rate of value-added loss, which is the lost value-added that would have been obtained if there had been no exogenous shocks divided by the value added without shocks. The bar plots are not stacked but cumulative. Each bar corresponds to a shock duration. The upper, middle, and lower rows correspond to the results of the complete connection, actual number, and single-connection models, respectively.

\section{Discussion and Conclusions}

This study showed how import and export shocks are propagated through domestic supply chains using actual Japanese supply-chain data and the WIOT. To connect firm-level supply chains to the input-output table, we proposed the complete connection, actual number, and single-connection models. Then, we estimated the value-added losses of Japanese firms caused by shocks originating in China, the EU and the US, and globally with different shocks magnitudes and durations.

The value-added loss rates differ with respect to where the shocks start. However, note that the losses triggered by the EU and the US and China are comparable to the global shocks even if the shares of trade for Japan are approximately one quarter and one fifth. Moreover, the comparison between models shows that the assignment of international connections to firms is very important, which indicates that the sectoral supply-chain data and model are insufficient to analyze realistic behavior. Instead, firm-level data and models are required. The losses increase sublinearly as the duration extends and superlinearly as the reduction rate increases, which are explained by the saturation speed and substitutability, respectively.

Since the present study discusses international shocks to Japanese firms, the results and the interpretations may not be applicable to other countries. For example, monocultural countries or countries highly dependent on imports or exports may have different behavior from that described in the present study. However, the importance of the present study is to show that firm-level supply-chain analysis differs from sector-level analysis. In fact, the scenarios of the countries show complicated behaviors that do not appear in the sector-level 
analysis, and the different durations and strengths of impacts also behave in a complicated manner that also does not appear in a sector-level analysis.

Most interpretations of our results concern imports, i.e., the supply side, since unlike supply-side disruption, there is no amplification for demand-side disruption. However, there are no connections between country sectors and the circulation of negative shocks between them can be nonlinear, and this is one of the limitations of this study. This issue falls beyond the scope of the present study.

Other limitations of this study should be mentioned. Since the number of connections between domestic firms and foreign sectors and their volumes are estimated, the results obtained in the present study may deviate from actual behavior. However, with limited data, our results can be considered some of the best estimations currently available. If data on every firm's import and export targets and their volume could be obtained, the estimations would be more precise. As mentioned above, we assume that supply chains are fixed in the model. In addition, our model ignores the prices of products and wages, which are incorporated in Colon et al. (2019); Otto et al. (2017). Our model assumes that similar to manufacturing inputs, service sector inputs can be stored as inventory. The domestic supply-chain data report only the locations of firm headquarters and not the locations of firm branches. Because firm headquarters are concentrated in Tokyo, production activities in Tokyo are most likely to be overvalued in our analysis.

As a future research direction, the author is collecting complete firm-level international trade data. Since the international trade data for each firm are estimations based on the models in the present study, a new study using the actual trade data would make it possible to discuss more realistic behavior of the international shocks and to verify the model proposed in the present study.

Funding: JP18K04615 and JP21H00743, Japan Society for the Promotion of Science. The JSPS TopicSetting Program to Advance Cutting-Edge Humanities and Social Sciences Research Area Cultivation. The Hyogo Earthquake Memorial 21 Century Research Institute. The Hyogo Science and Technology Association.

Data Availability Statement: The data for supply chain network are based on a survey done by Tokyo Shoko Research (TSR), one of the leading credit research agencies in Tokyo, supplied to us through the Research Institute of Economy, Trade and Industry (RIETI). The data are not in the public domain but are commercially available from Tokyo Shoko Research, Ltd., Available online: http:/ / www.tsr-net.co.jp/ (accessed on 8 May 2012), webmaster@tsr-net.co.jp. The authors had no special access privileges to the data.

Acknowledgments: This research was conducted as part of a project entitled "Dynamics of Economy and Finance from the Economic Network Point of View" undertaken at the Research Institute of Economy, Trade, and Industry (RIETI). The authors are grateful for financial support from JSPS Kakenhi Grant Nos. JP18K04615 and JP21H00743; the JSPS Topic-Setting Program to Advance Cutting-Edge Humanities and Social Sciences Research Area Cultivation; the Hyogo Earthquake Memorial 21 Century Research Institute; and the Hyogo Science and Technology Association. The authors thank Kohsuke Araki, Takeshi Tsumuro, and Mizuki Koga for providing technical support for this study.

Conflicts of Interest: The author declares no conflict of interest.

\section{References}

Ayadi, Rym, Giorgia Giovannetti, Enrico Marvasi, Giulio Vannelli, and Chahir Zaki. 2021. Demand and Supply Exposure through Global Value Chains: Euro-Mediterranean Countries during COVID. The World Economy 113: 73-88.

Baldwin, Richard, and Javier Lopez-Gonzalez. 2015. Supply-chain trade: A portrait of global patterns and several testable hypotheses. The World Economy 38: 1682-721. [CrossRef]

Barabási, Albert-László. 2016. Network Science. Cambridge: Cambridge University Press.

Battiston, Stefano, Domenico Delli Gatti, Mauro Gallegati, Bruce Greenwald, and Joseph E. Stiglitz. 2007. Credit chains and bankruptcy propagation in production networks. Journal of Economic Dynamics and Control 31: 2061-84. [CrossRef]

Chongvilaivan, Aekapol. 2012. Thailand's 2011 Flooding: Its Impact on Direct Exports and Global Supply Chains. Technical report, ARTNeT working paper series. Berlin: ARTNeT. 
Chowdhury, Priyabrata, Sanjoy Kumar Paul, Shahriar Kaisar, and Md. Abdul Moktadir. 2021. COVID-19 pandemic related supply chain studies: A systematic review. Transportation Research Part E: Logistics and Transportation Review 148: 102271. [CrossRef]

Christopher, Martin. 2016. Logistics E Supply Chain Management. Upper Saddle River: Financial Times Press.

Colon, Celian, Stephane Hallegatte, and Julie Rozenberg. 2019. Transportation and Supply Chain Resilience in the United Republic of Tanzania: Assessing the Supply-Chain Impacts of Disaster-Induced Transportation Disruptions. Washington, DC: World Bank.

Coronavirus Resource Center. 2020. Coronavirus COVID-19 Global Cases by the Center for Systems Science and Engineering (CSSE) at Johns Hopkins University. Available online: http:/ / coronavirus.jhu.edu/map.html (accessed on 21 April 2021).

Dietzenbacher, Erik, Bart Los, Robert Stehrer, Marcel Timmer, and Gaaitzen de Vries. 2013. The construction of world input-output tables in the WIOD project. Economic Systems Research 25: 71-98. [CrossRef]

Feenstra, Robert C. 1998. Integration of trade and disintegration of production in the global economy. Journal of Economic Perspectives 12: 31-50. [CrossRef]

Fujiwara, Yoshi, and Hideaki Aoyama. 2010. Large-scale structure of a nation-wide production network. The European Physical Journal B 77: 565-80. [CrossRef]

Gatti, Domenico Delli, Corrado Di Guilmi, Edoardo Gaffeo, Gianfranco Giulioni, Mauro Gallegati, and Antonio Palestrini. 2005. A new approach to business fluctuations: Heterogeneous interacting agents, scaling laws and financial fragility. Journal of Economic Behavior \& Organization 56: 489-512.

Gereffi, Gary, John Humphrey, and Timothy Sturgeon. 2005. The governance of global value chains. Review of International Political Economy 12: 78-104. [CrossRef]

Guan, Dabo, Daoping Wang, Stephane Hallegatte, Steven J. Davis, Jingwen Huo, Shuping Li, Yangchun Bai, Tianyang Lei, Qianyu Xue, D'Maris Coffman, and et al. 2020. Global supply-chain effects of COVID-19 control measures. Nature Human Behaviour 4: 577-87. [CrossRef]

Hallegatte, Stéphane. 2008. An adaptive regional input-output model and its application to the assessment of the economic cost of Katrina. Risk Analysis 28: 779-99. [CrossRef]

Hallegatte, Stéphane. 2012. Modeling the Roles of Heterogeneity, Substitution, and Inventories in the Assessment of Natural Disaster Economic Costs. Washington, DC: The World Bank.

Hallegatte, Stéphane. 2014 Modeling the role of inventories and heterogeneity in the assessment of the economic costs of natural disasters. Risk Analysis 34: 152-67. [CrossRef] [PubMed]

Hallegatte, Stéphane, and Fanny Henriet. 2008. Assessing the Consequences of Natural Disasters on Production Networks: A Disaggregated Approach. FEEM Working Paper. No. 100.2008. Available online: https://ssrn.com/abstract=1318335 (accessed on 1 June 2020).

Henriet, Fanny, Stéphane Hallegatte, and Lionel Tabourier. 2012. Firm-Network Characteristics and Economic Robustness to Natural Disasters. Journal of Economic Dynamics and Control 36: 150-67. [CrossRef]

Hiroyasu, Inoue, and Todo Yasuyuki. 2020. The propagation of the economic impact through supply chains: The case of a mega-city lockdown against the spread of COVID-19. PLoS ONE 15: e0239251.

Inoue, Hiroyasu, and Yasuyuki Todo. 2019a. Firm-level propagation of shocks through supply-chain networks. Nature Sustainability 2: 841-47. [CrossRef]

Inoue, Hiroyasu, and Yasuyuki Todō. 2019b. Propagation of Negative Shocks through Firm Networks: Evidence from Simulation on Comprehensive Supply-Chain Data. PLoS ONE 14: 3. [CrossRef]

Inoue, Hiroyasu, Yohsuke Murase, and Yasuyuki Todo. 2021a. Do Economic Effects of the "Anti-COVID-19" Lockdowns in Different Regions Interact through Supply Chains? PLoS ONE 16: e0255031. [CrossRef]

Inoue, Hiroyasu, Yohsuke Murase, and Yasuyuki Todo. 2021b. Lockdowns need geographic coordination because of propagation of economic effects through supply chains. Social Science Research Network. [CrossRef]

Kimura, Fukunari, and Mitsuyo Ando. 2005. Two-dimensional fragmentation in East Asia: Conceptual framework and empirics. International Review of Economics \& Finance 14: 317-48.

MIC. 2013. Japan Standard Industrial Classification (Revision 13). Available online: https://www.soumu.go.jp/english/dgpp_ss/ seido/sangyo/index13.htm (accessed on 1 June 2020).

Ministry of Economy, Trade and Industry. 2011. White Paper on International Economy and Trade. Tokyo: METI Tokyo.

Ministry of Finance. 2021. Trade Statistics of Japan. Available online: https://www.customs.go.jp/toukei/info/index_e.htm (accessed on 10 June 2021).

Ministry of Internal Affairs and Communications, the Cabinet Office, the Financial Services Agency, the Ministry of Finance, the Ministry of Education, Culture, Sports, Science and Technology, the Ministry of Health, Labour and Welfare, the Ministry of Agriculture, Forestry and Fisheries, the Ministry of Economy, Trade and Industry, the Ministry of Land, Infrastructure, Transport and Tourism, and the Ministry of Environment, Japan. 2015. Input-Output Tables for Japan. Available online: https:/ / www.soumu.go.jp/english/dgpp_ss/data/io/index.htm (accessed on 1 June 2020).

Ministry of Trade, Enterprise and Industry. 2019. Preliminary Report of 2019 (26th) Basic Survey of Japanese Business Structure and Activities (Definite Reports). Available online: https://www.meti.go.jp/english/statistics/tyo/kikatu/2019_26th.html (accessed on 7 April 2021).

Otto, Christian, Sven N. Willner, Leonie Wenz, Katja Frieler, and Anders Levermann. 2017. Modeling loss-propagation in the global supply network: The dynamic agent-based model acclimate. Journal of Economic Dynamics and Control 83: 232-69. [CrossRef] 
Paul, Sanjoy Kumar, and Priyabrata Chowdhury. 2020. A production recovery plan in manufacturing supply chains for a high-demand item during COVID-19. International Journal of Physical Distribution \& Logistics Management 51: 104-25.

Statistics Division, Department of Economic and Social Affairs, United Nations. n.d. International Standard Industrial Classification. Available online: https://unstats.un.org/unsd/classifications/Econ/ISIC.cshtml (accessed on 7 April 2021).

Thomas, Douglas, and Jennifer Helgeson. 2021. The effect of natural/human-made hazards on business establishments and their supply chains. International Journal of Disaster Risk Reduction 59: 102257. [CrossRef]

Timmer, Marcel P., Erik Dietzenbacher, Bart Los, Robert Stehrer, and Gaaitzen J. de Vries. 2015. An illustrated user guide to the world input-output database: The case of global automotive production. Review of International Economics 23: 575-605. [CrossRef]

Weisbuch, Gérard, and Stefano Battiston. 2007. From production networks to geographical economics. Journal of Economic Behavior E Organization 64: 448-69.

World Bank. 2020. World Development Report 2020. Washington, DC: World Bank Publications.

Ye, Linghe, and Masato Abe. 2012. The Impacts of Natural Disasters on Global Supply Chains. ARTNeT working paper series. Bangkok: Asia-Pacific Research and Training Network on Trade (ARTNeT). 